\title{
As ilustrações no livro Geometria Prática de Olavo Freire e a apropriação do Método Intuitivo
}

Alexsandra Camara

Zenildo Santos

\section{Resumo}

O presente estudo analisou as ilustrações apresentadas no livro Geometria Prática, de Olavo Freire, com o objetivo de compreender como elas estavam relacionadas às propostas pedagógicas que eram veiculadas no início do período Republicano no Brasil. Foi possível identificar os tipos e funções relacionadas às ilustrações, o que possibilitou a realização de uma discussão sobre conteúdos e métodos que faziam parte do ensino da Geometria. Como resultado, verifica-se que a apropriação criativa das metodologias e das ilustrações auxiliou o autor na propagação do método intuitivo por meio de seu livro didático.

Palavras-chave: Ilustrações. Geometria. Método intuitivo 


\title{
The illustrations in the Olavo Freire Practical Geometry book and the appropriation of the Intuitive Method
}

\author{
Alexsandra Camara \\ Zenildo Santos
}

\section{Abstract}

The present study was based on the illustrations that were not related to the geometry of the children, and Olavo Freire, in order to understand the pedagogical issues that were presented at the beginning of the republican period in Brazil. A. He was able to perform the types and functions related to the illustrations, which made possible a session on the subjects and methods that are part of the teaching of Geometry. As a result, it verifies whether a creative appropriation of methodologies and illustrations favors the propagation of the intuitive method through its textbook.

Keywords: Illustrations. Geometry. Intuitive method. 


\section{Introdução}

Muito utilizada na literatura infantil e nas peças publicitárias, as ilustrações também são encontradas nos livros e manuais didáticos. Sua disposição no texto, por vezes, apresenta uma função, ainda que decorativa ou com um fim específico.

Uma ilustração tem o objetivo de compilar, de forma abstrata, as definições dos conceitos transmitidos que, por vezes, só com o texto escrito, acabam não sendo compreendidos adequadamente. Nesse sentido, o tipo de ilustração utilizada pode trazer elementos e informações essenciais à compreensão daquilo que está sendo descrito.

Esse texto foi produzido a partir do debate e discussão da disciplina Análise de ilustrações em materiais escolares, oferecido pelo Programa de Pós-Graduação em Educação e Saúde na Infância e na Adolescência, da Universidade Federal de São Paulo que teve como objetivo discutir o estudo dos tipos e funções das ilustrações pautado teoricamente por Liliane Vezin (1986) e Jean François Vezin (1986).

Nesse contexto, escolheu-se analisar um livro didático pelo fato de que, segundo Chartier (1990), eles configuram um objeto em circulação, sendo veículos de movimentação de ideias que traduzem valores e comportamentos que se desejou que fossem ensinados. A relação entre livro didático e escolarização ${ }^{127}$ permite pensar na possibilidade de uma aproximação do ponto de vista histórico com relação às concepções sobre o que a escola deveria ensinar e qual concepção educativa era presente na formação dos sujeitos escolares.

A escolha do objeto específico de análise foi o livro Geometria Prática, de Olavo Freire $^{128}$ (1930). Sua boa aceitação pela imprensa e o fato de ter sido a primeira obra didática para o ensino primário de Geometria no período da Velha República fizeram com que ele estivesse em indicações de livros nas primeiras décadas do século $\mathrm{XX}$, em vários estados brasileiros, entre eles São Paulo, Paraná e Santa Catarina (LEME DA SILVA; VALENTE, 2014).

\footnotetext{
127 Entende-se por Escolarização o conjunto de conhecimentos adquiridos na escola. AURÉLIO. Dicionário do Aurélio Online 2018. Disponível em: <https://dicionariodoaurelio. com/escolarizacao>. Acesso em: 20 Abr. 2019.

${ }_{128}$ De acordo com D’Esquivel (2018), Olavo Freire foi aluno do Colégio Menezes Vieira e chamou a atenção desde cedo do diretor e fundador da escola devido ao seu bom desempenho escolar. No ano de 1890, assumiu a função de Conservador do Pedagogium, órgão da administração pública do qual Menezes Vieira foi fundador e diretor. Freire tinha a função de um gestor cuja responsabilidade era gerenciar as atividades do museu pedagógico, zelar pela manutenção do acervo, organizar as exposições e ministrar cursos a professores primários. Atuou como professor de Trabalhos Manuais na escola São José e na Escola Normal do Distrito Federal, além de professor em escolas primárias do estado Rio de Janeiro. Também se tornou autor de livros didáticos de várias matérias, entre elas: Geografia, Aritmética, trabalhos manuais, Geometria, confecções de mapas, cadernos de desenhos e caligrafias, todas publicadas pela Livraria Francisco Alves. Algumas dessas obras alcançaram grande sucesso editorial.
} ISSN 2526-2882 
Figura 1 - Capa do Livro Noções de Geometria Prática (1930)

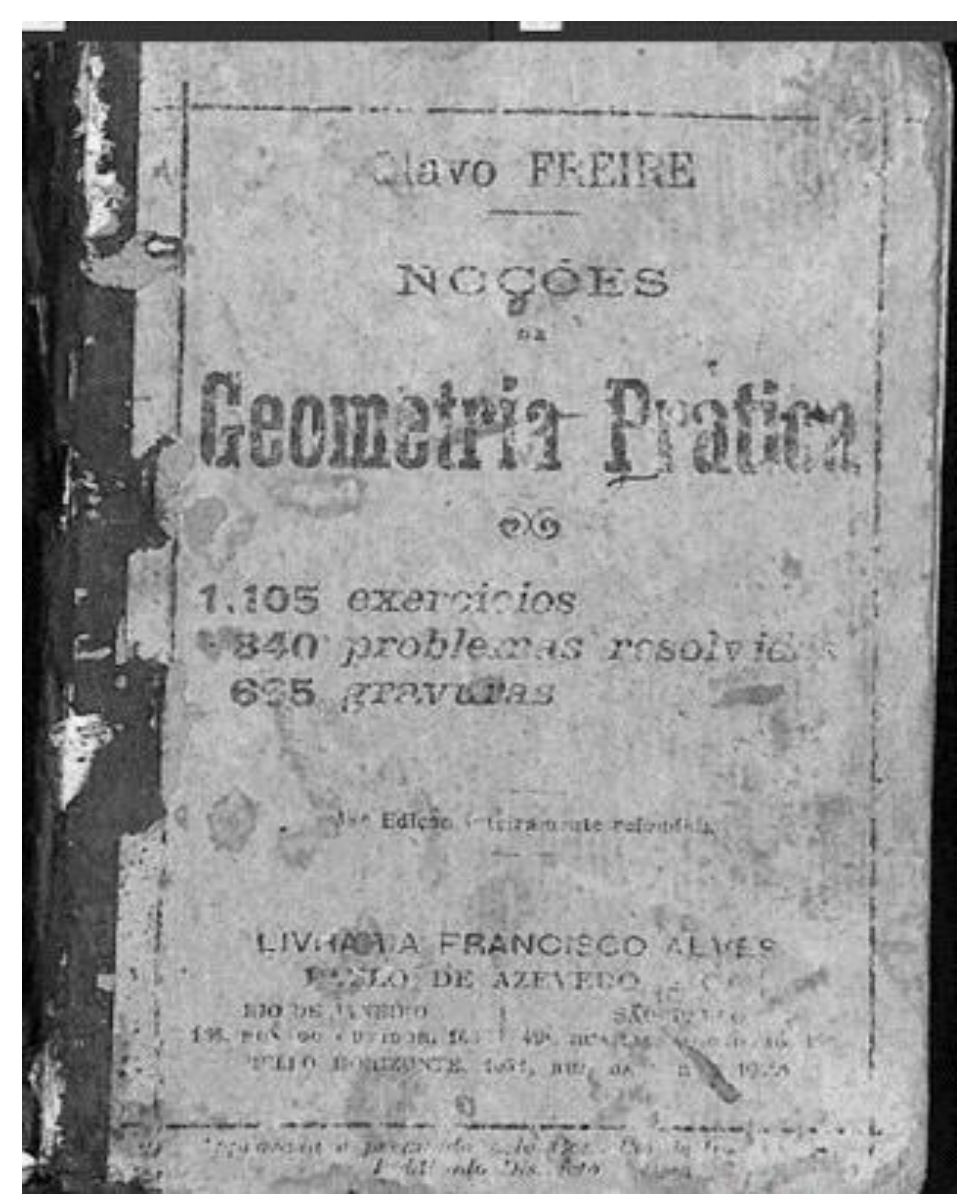

Fonte: Freire (1930)

Nessa época, em relação ao ensino primário, os programas prescritos apresentavam mais detalhes quanto às indicações dos conteúdos a serem ensinados em cada matéria e em cada série em relação ao período imperial. Muitos saberes e metodologias foram introduzidos nas indicações para o ensino primário brasileiro com o objetivo de formar o novo cidadão republicano (SOUZA, 2009).

Um dos documentos que influenciou as referidas alterações é o parecer de Rui Barbosa $^{129}$, intitulado Reforma do ensino primário e várias instituições complementares da instrução pública (1883), que constitui uma das primeiras obras e a mais completa delas sobre a organização pedagógica da escola primária e sobre política de educação popular produzida

129 No livro, resultado de sua tese de doutoramento, intitulado Rui Barbosa: pensamento e ação, Maria Cristina Gomes Machado apresenta elementos importantes dessa figura exponencial da história da educação brasileira. Segundo a autora, "Rui Barbosa elegeu-se deputado provincial na Bahia, em 1878, e no ano seguinte elegeu-se deputado geral, tendo participado da vida pública nacional por quase cinquenta anos. Deixou uma imensa obra, tanto em extensão quanto em profundidade. Foi autor de diversos projetos, pareceres, artigos para jornais, discursos, conferências e trabalhos jurídicos. Estudou Direito e foi intelectual autodidata, erudito, conhecedor de diversos idiomas e atuou em várias áreas" (MACHADO, 2002, p. 2).

ISSN 2526-2882

$$
\text { * } 342 *
$$


no Brasil no século XIX, em que o método intuitivo é considerado como o elemento mais importante das novas propostas educacionais.

O método foi difundido na Europa no final do século XIX e valorizava o uso dos sentidos e da observação como base de todo aprendizado. Sistematizado por Pestalozzi, que acreditava a educação intelectual resulta da organização das impressões sensoriais obtidas pela relação homem-natureza. De acordo com Pestalozzi (1946, p. 63), "intuição da natureza é o único fundamento próprio e verdadeiro da instrução humana, porque é o único alicerce do conhecimento humano". Para ele, o desenvolvimento da capacidade de percepção e observação dos alunos era mais importante que ensinar determinados conhecimentos.

No Brasil, o método foi difundido com a publicação da obra "Lição das Coisas", traduzido por Rui Barbosa em 1880. O manual originalmente publicado nos Estados Unidos, em 1861, Primary object lessons for a graduated course of development por Calkins.

Estudos de Valdemarin (2004) mostraram que, em meados do século XIX, o método intuitivo era entendido como um instrumento pedagógico capaz de auxiliar na melhoria do ensino escolar que se mostrava insuficiente para a formação do novo trabalhador industrial. Para o método intuitivo, a educação teria início no próprio corpo da criança que, por meio dos sentidos e da observação, estaria em contato com os mais variados objetos, investindo contra o caráter abstrato e sem utilidade que a escola estava propagando. De acordo com a autora, o método,

consiste num instrumento pedagógico capaz de reverter à ineficiência do ensino escolar, não somente no aspecto metodológico, mas também, na sua função para a política e para a estabilização do regime republicano, com a instituição do sufrágio universal, o Estado necessita de cidadãos que saibam ler, escrever. E a escola primária era a peça fundamental para a difusão do sistema de valores burgueses, devendo a ele adequar-se cultural e economicamente (VALDEMARIN, 2004, p. 69).

Dessa forma, procurou-se analisar o livro Geometria Prática, de Olavo Freire (1930), com o objetivo de compreender como as ilustrações apresentadas em seu texto estavam relacionadas às propostas pedagógicas que eram veiculadas no período da República Velha no Brasil.

\section{A análise das ilustrações}

A edição ${ }^{130}$ do livro de Freire examinada é a de número 35, de 1930, que como denomina na capa, apresenta 1105 exercícios, 340 problemas resolvidos e 665 ilustrações que são analisadas nesse artigo.

${ }^{130}$ D’Esquivel (2018) mostra as várias edições que a obra sofreu até a década de 1960. A novidade de cada reedição era o acréscimo de novos problemas e exercícios, mudança que era estampada na capa como propaganda para as ISSN 2526-2882 
A ilustração é uma representação de um objeto ou uma situação real que é expressa mais ou menos realisticamente. É, na verdade, uma figuração materializada e não uma figuração cognitiva na medida em que não é apenas internalizada na forma de uma representação mental, mas desenhada (VEZIN, L., 1986, p. 110).

Por essa ótica, a autora entende como ilustração qualquer imagem que acompanha um texto com o objetivo de dar-lhe significado, podendo ser desenho, esquema, fotografia, gráfico, croquis, entre outros, que especificam a informação conceitual a ser adquirida.

Ao realizar a análise dessas ilustrações, por capítulo da obra, foram obtidos os resultados apresentados no Quadro 1.

Quadro 1 - Quantidade de ilustrações por capítulos

\begin{tabular}{|c|c|c|}
\hline Capítulos & \begin{tabular}{c|}
$\begin{array}{c}\text { Quantidade de } \\
\text { figuras }\end{array}$ \\
\end{tabular} & Conteúdos abordados \\
\hline Capítulo 1 & 25 & Espaço, corpo, extensão, volume, superfície, linha e ponto. \\
\hline Capítulo 2 & 38 & Ângulos, divisão de ângulo e bissetriz. \\
\hline Capítulo 3 & 17 & Perpendiculares e Oblíquas. \\
\hline Capítulo 4 & 20 & Paralelas, linha convergente e linha divergente. \\
\hline Capítulo 5 & 105 & Triângulos retilíneos e casos de igualdade entre triângulos. \\
\hline Capítulo 6 & 60 & Quadriláteros, quadrado, losango, retângulo, paralelogramo e trapézio. \\
\hline Capítulo 7 & 45 & $\begin{array}{l}\text { Circunferência, círculo, raio, diâmetro, arco, corda, flecha, secante, tangente, } \\
\text { segmento, setor, ângulo central, ângulo inscrito, circunferência concêntrica e } \\
\text { excêntrica, coroa circular, circunferências tangente e traçado da circunferência. }\end{array}$ \\
\hline Capítulo 8 & 58 & $\begin{array}{l}\text { Polígonos, polígonos regulares, irregulares, inscritos, circunscritos, estrelados, } \\
\text { medidas de ângulos, divisão da circunferência. }\end{array}$ \\
\hline Capítulo 9 & 10 & Linhas proporcionais. \\
\hline Capítulo 10 & 14 & Polígonos semelhantes e escalas. \\
\hline Capítulo 11 & $\mathrm{O}$ & Relação entre a circunferência e o diâmetro. \\
\hline Capítulo 12 & 63 & Áreas dos polígonos, áreas das figuras circulares, figuras equivalentes. \\
\hline Capítulo 13 & 12 & Linha reta e o plano. \\
\hline Capítulo 14 & 9 & Ângulos diedros, ângulo sólido ou poliedro. \\
\hline Capítulo 15 & 31 & Poliedros. \\
\hline Capítulo 16 & 26 & Prisma e pirâmide. \\
\hline Capítulo 17 & 25 & Corpos redondos. \\
\hline Capítulo 18 & 1 & Áreas dos poliedros e dos corpos redondos. \\
\hline Capítulo 19 & 20 & Volumes dos poliedros e corpos redondos. \\
\hline Capítulo 20 & 15 & Concordância de linhas. \\
\hline Capítulo 21 & 71 & Elipse, falsa elipse, oval, espiral, voluta, hélice, parábola e hipérbole. \\
\hline
\end{tabular}

Fonte: Os autores (2018).

Dos vinte e um capítulos, apenas o capítulo 11, relativo ao estudo da relação entre circunferência e diâmetro, não apresentou ilustrações. O capítulo com menor número é o 8, que aborda as áreas dos poliedros e dos corpos redondos, com uma única ilustração. O capítulo 5, dedicado ao aprendizado de triângulos retilíneos e casos de igualdade entre triângulos, é o que contém maior número de imagens, sendo cento e cinco no total.

próximas vendas. Ainda segundo o pesquisador, essas sucessivas reedições são devidas à capacidade do editor e ao fato de que os saberes geométricos apresentados na obra apresentavam boa aceitação na escola elementar. ISSN 2526-2882 
Percebe-se grande diferença entre os capítulos com maior e menor número de ilustrações. O autor utilizou poucas ilustrações nos capítulos dedicados aos conteúdos que apresentam muitas fórmulas e priorizou o uso desse recurso para os capítulos que trabalhavam mais com as construções geométricas e as demonstrações de teoremas no sentido de auxiliar quanto à compreensão desses temas que são considerados mais difíceis que as situações de definições e de cálculos de área e volume.

A importância do uso de ilustrações no campo educacional destaca a necessidade de determinar as correspondências que realmente existem entre os dados verbais e as ilustrações para especificar seu status na comunicação da informação e responde a uma necessidade de informação em relação aos dados verbais correspondentes (VEZIN, L., 1986, p. 110, tradução nossa).

De acordo com a autora, o uso de uma ilustração visa uma comunicação com o texto verbal e fornece pistas ou acrescenta informações, servindo para fixar a atenção e concretizar um discurso. Assim, no caso das construções e dos teoremas, situações de mais difícil entendimento, as ilustrações apareciam como forma de auxiliar o texto escrito quanto ao seu objetivo de informar tais conhecimentos geométricos ao leitor.

Nas páginas iniciais do livro de Freire (1930), há algumas transcrições de indicações de jornais da época. O jornal O Paiz, em abril de 1985, diz que "os numerosos exercícios e problemas praticos e as nitidas e bem aplicadas gravuras que encerra o compendio do Sr. Olavo Freire elucidam cabalmente a matéria, cujo ensino, amenizado d'essa forma, torna-se tarefa agradável e facil ao professor e ao discipulo” (FREIRE, 1930, p. 8).

A indicação da obra expressa no Jornal faz menção a importância das gravuras utilizadas pelo autor para compor a explanação do conteúdo. Em conjunto com os exercícios e os problemas possibilitariam o aprendizado mais agradável. No nosso entendimento, essa opinião encontra apoio no método intuitivo, vez que utilizando os sentidos e a observação, o aluno chegaria ao aprendizado.

Nessa condição, as imagens expostas por Freire (1930) estão intencionalmente complementando o conteúdo, e em algumas situações, são o próprio conteúdo, se falam por si mesmas.

O uso de ilustrações é um dos elementos do livro de Freire bastante elogiado pela imprensa. Assim, foi possível verificar a importância que era dada às ilustrações de livros didáticos na época de estudo.

Liliane Vezin (1986) e Jean-François Vezin (1986) informam que as ilustrações podem assumir diferentes tipologias em determinado texto. Ao realizar um levantamento quanto aos tipos de ilustrações, verificou-se a existência de desenhos, esquemas e desenhos esquematizados, conforme apresenta o Gráfico 1. 


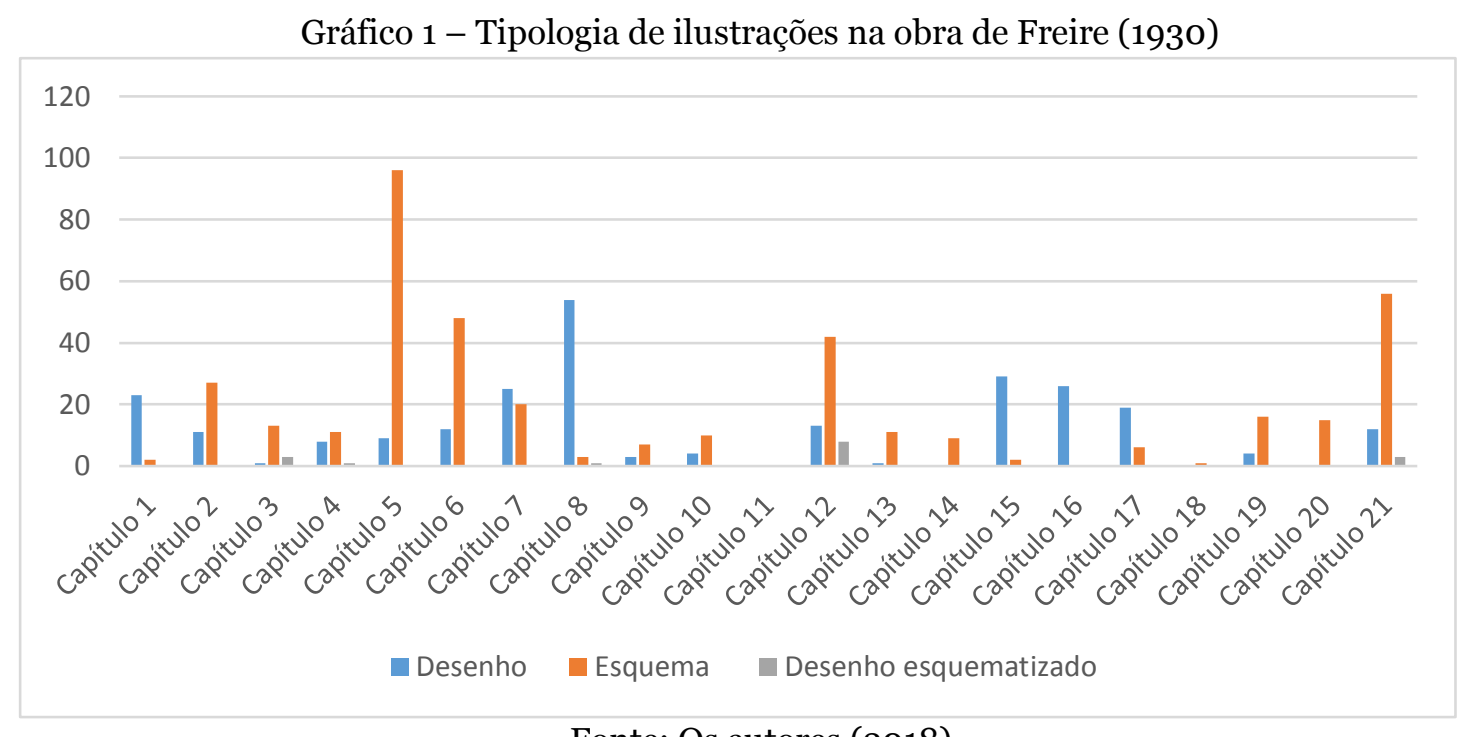

Fonte: Os autores (2018)

Nas ilustrações analisadas, verificou-se que 38,2\% são desenhos, 59,4\% são esquemas e 2,4\% representam os desenhos esquematizados. Para Vezin, L., (1986, p. 71), o “[...] esquema fornece uma expressão não verbal do que está sendo aprendido, concentrando a atenção no essencial”. O desenho indica um objeto da classe em sua particularidade e distingue determinado objeto da classe em comparação aos outros (VEZIN, L., 1986).

Pesquisas realizadas por Vezin L. (1986) também mostram que as ilustrações podem assumir diferentes funções dentro de um contexto e auxiliar na aprendizagem de textos orais e escritos. Entre as funções indicadas pelo autor, verifica-se que a obra de Freire apresenta a motivacional e contextual, a explicativa descritiva e a explicativa funcional, conforme indica o Gráfico 2.

Gráfico 2 - Funções das ilustrações na obra Freire (1930)

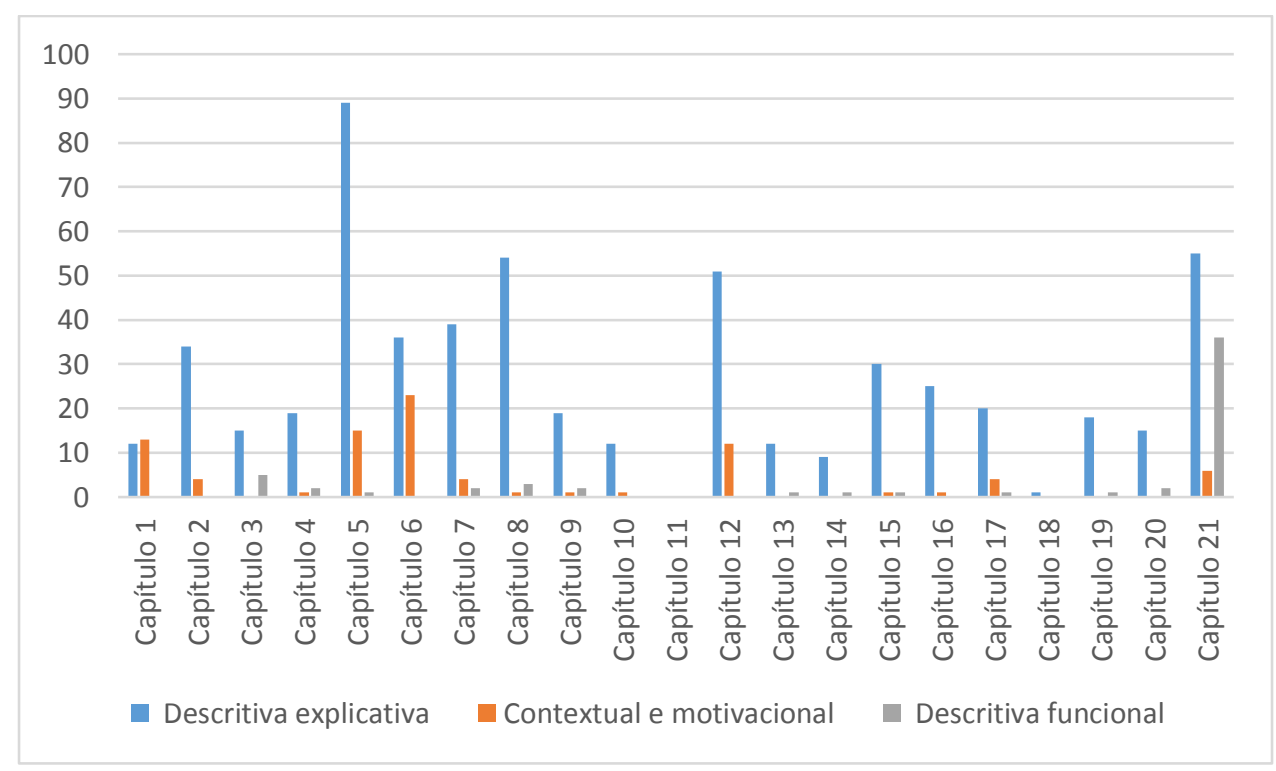

Fonte: Elaborado pelos autores (2018).

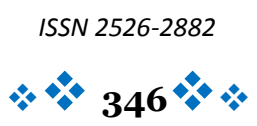


$\mathrm{Na}$ análise realizada, percebe-se que $79,6 \%$ das ilustrações apresentam a função descritiva explicativa, 12,3\% caracterizam a função descritiva contextual motivacional, enquanto 8,2\% estão relacionadas à descritiva funcional, sendo importante comentar que uma ilustração pode ser identificada com mais de uma função.

A função motivacional e contextual é utilizada para atrair a atenção e contextualizar o objeto de estudo. A função explicativa descritiva utiliza a ilustração com o objetivo de fornecer uma representação do que, às vezes, é difícil de ser explicado somente com o texto escrito ou oral. A terceira função, explicativa funcional, permite fazer com que o leitor visualize a apresentação de um processo ou mecanismo (VEZIN, L., 1986).

A seguir, são apresentados alguns exemplos de ilustrações utilizadas por Freire (1930), a fim de analisar suas tipologias e funções. Face ao exposto, a tipologia mais utilizada foi o esquema com maior incidência no capítulo 5, que estuda os triângulos retilíneos e os casos de igualdade entre triângulos. O capítulo que apresentou menor número de esquema foi o 18, aparecendo apenas uma vez. Na figura 2, apresenta-se um exemplo de esquema utilizado na obra.

Figura 2 - Exemplo de esquema e função explicativa descritiva

A extensão com uma unica dimensão : comprimento, chama-se linha.

Um fio muito fino, um traço feito com giz

LINHA ou lapis sobre uma superficie podem ser considerados como linhas, porém pouco perfeitas; porque, por melhor que os façamos, sempre haverá uma largura ou uma espessura, e a linha geometrica não tem largura nem espessura, porém unicamente comprimento. Entretanto para representarmos a linha

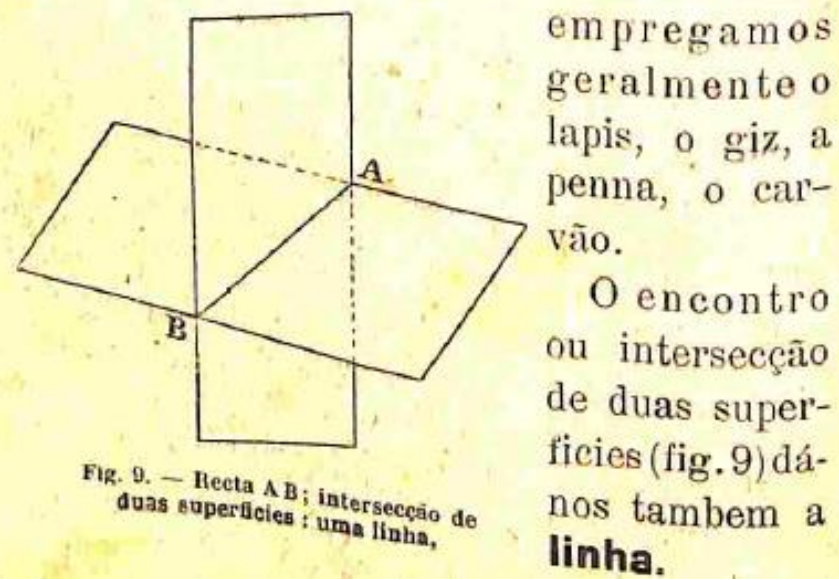

Fonte: Freire (1930, p. 16).

ISSN 2526-2882

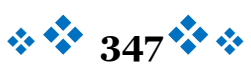


Ao explicar sobre a definição de linha, o autor utiliza uma ilustração que indica a intersecção de dois planos, obtendo a reta $\mathrm{AB}$. Assim, é possível verificar que os esquemas destacam as principais informações, isto é, as particularidades de um determinado conhecimento que se quer destacar no processo de ensino e aprendizagem. Eles orientam a atividade para as características gerais válidas para um conjunto de objetos ou fenômenos e focalizam a atenção no que é essencial para a compreensão de determinado conceito, definição ou propriedade.

Entre as ilustrações analisadas, verifica-se que a maioria delas apresenta a função explicativa descritiva, que é o que ocorre na ilustração apresentada na figura 2. Para mostrar que a interseção de dois planos é uma linha, o autor utiliza um esquema para auxiliar o aluno quanto à compreensão desse resultado. Assim, a ilustração tem como função apresentar uma representação desse objeto, o que ficaria mais difícil de explicar somente com o texto escrito que acompanha o esquema.

Comentando as características de um esquema, Peraya e Nyssen (1994) afirmam que uma delas é fazer a mediação entre um conceito abstrato e a constituição de uma imagem mental dele. Nesse caso, a natureza do esquema é fazer uma representação figurativa e analógica, o que possibilitaria a concretização de conceitos ou fenômenos que são difíceis de representar.

A necessidade dessa concretização para o ensino da Geometria foi indicada no relatório de Rui Barbosa, em que ele considera que o seu ensino deveria ser desenvolvido pelos métodos concretos e intuitivo, pois "É por meio de modelos materiais, de construções gráficas, que há de ter entrada na escola o curso, sempre concreto, intuitivo, figurado, dos elementos desta ciência" (BARBOSA, 1883, p. 289).

Era a partir do contato com objetos e com as ilustrações que a criança desenvolveria suas capacidades de percepção e suas faculdades de observação. O ensino partindo do concreto para o abstrato configurava-se como uma característica do modelo de ensino intuitivo e, nesse contexto, o uso da ilustração, como apresentado por Freire, auxiliaria na implementação do referido método no ensino da Geometria da escola primária.

Além da função explicativa descritiva, também se observam ilustrações que apresentam uma função explicativa funcional, totalizando 9,71\% do total, conforme pode-se verificar na Figura 3. 
Figura 3 - Exemplo de esquema e função explicativa funcional

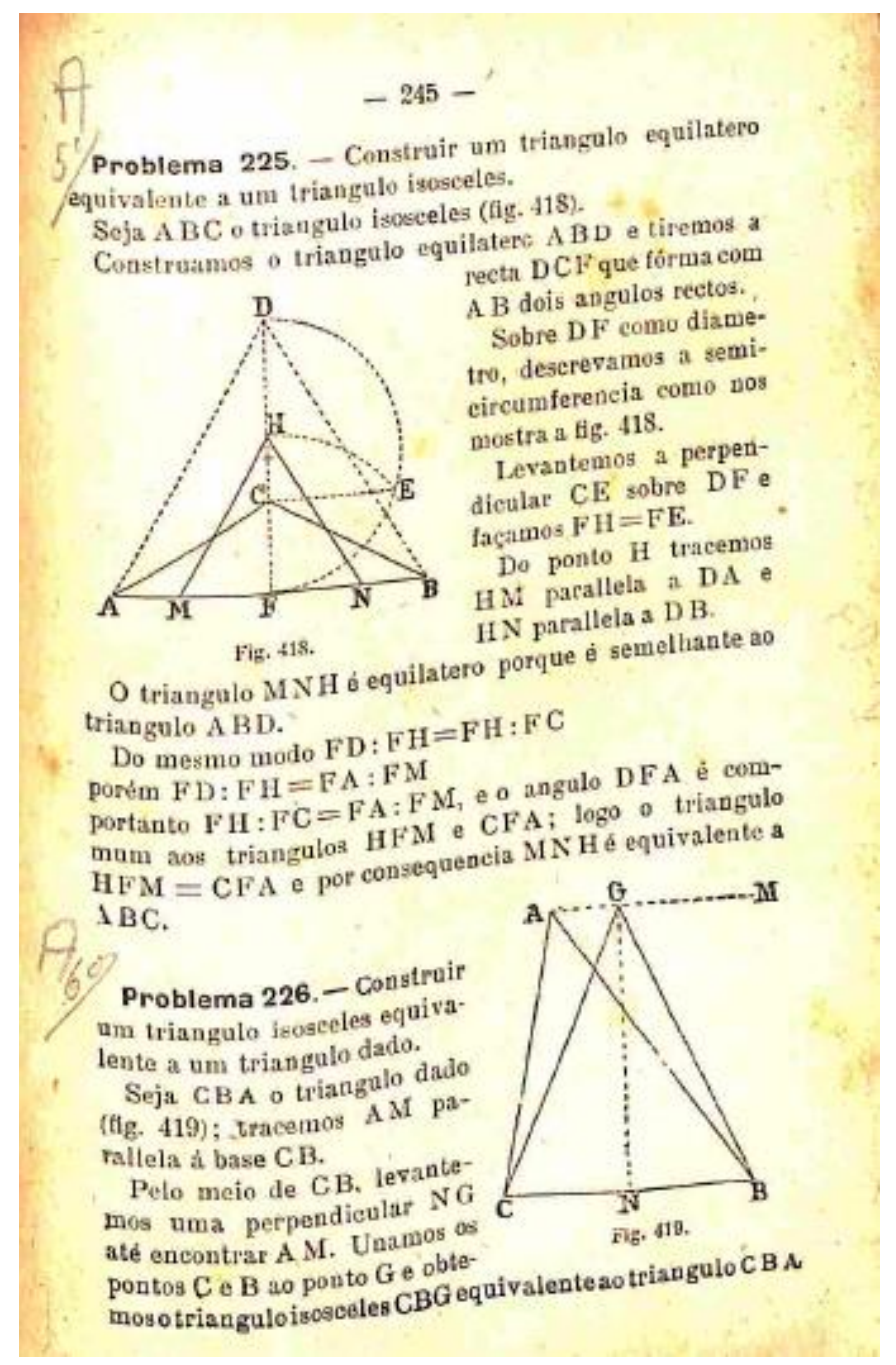

Fonte: Freire (1930, p. 245).

Para a construção de um triângulo equilátero equivalente a um triângulo isósceles, problema 25 da figura 3, são necessárias várias construções geométricas, que poderiam dificultar a resolução do referido problema. Dessa forma, a proposta é que a figura auxilie quanto à compreensão dos passos necessários a essa construção, fazendo com que sejam indicadas cada uma dessas construções por meio de linhas tracejadas.

Em terras paulistas, o uso de instrumentos no ensino primário foi confirmado por Souza (2009) ao apresentar em seu livro, Alicerces da Pátria, um exame de Geometria do $3^{\circ}$ ano do Grupo Escolar Antonio Padilha, de 1896, na cidade de Sorocaba, estado de São Paulo. O problema "Traçar a bissetriz de um ângulo ou dividi-lo em duas partes iguais" é dado pela professora A. P. Ourique de Carvalho para a aluna Dorvalina de Moraes Rosa, que responde corretamente à questão. 
Essa forma de pensar o ensino de Geometria também foi constatada por Leme da Silva e Valente (2014) ao analisarem o modelo de organização escolar criado pelos grupos escolares paulistas nas primeiras décadas republicanas. Os autores relatam que a realização de construções geométricas com o uso de instrumentos trazia a ideia de o ensino ser prático e que a primeira evidência desses tipos de atividades no estado de São Paulo é apresentada em 1894, com a publicação da primeira edição do livro de Olavo Freire.

As construções propostas por Freire apresentam uma sequência de passos rígidos até obter a figura geométrica final, conforme pode-se observar nas construções apresentadas na figura 3. Para Leme da Silva (2018), "Educar a mão com traços firmes é entendido como usar bem a régua, e educar a vista significa empregar adequadamente o esquadro e o compasso, de modo a obter medidas iguais de lados e ângulos” (p. 365).

Dessa forma, a prática com os traçados das figuras geométricas promoveria a educação da mão e da vista, concepções essenciais na aplicação do método intuitivo. Para essas situações, as ilustrações tiveram a função de auxiliar o leitor quanto ao desenvolvimento dos inúmeros passos que eram necessários, fazendo com que fosse possível a realização de contruções geométricas no ensino primário graças aos esquemas com a função descritiva funcional que foram introduzidos por Freire ao longo de seu texto escrito.

Figura 4 - Exemplo de desenho

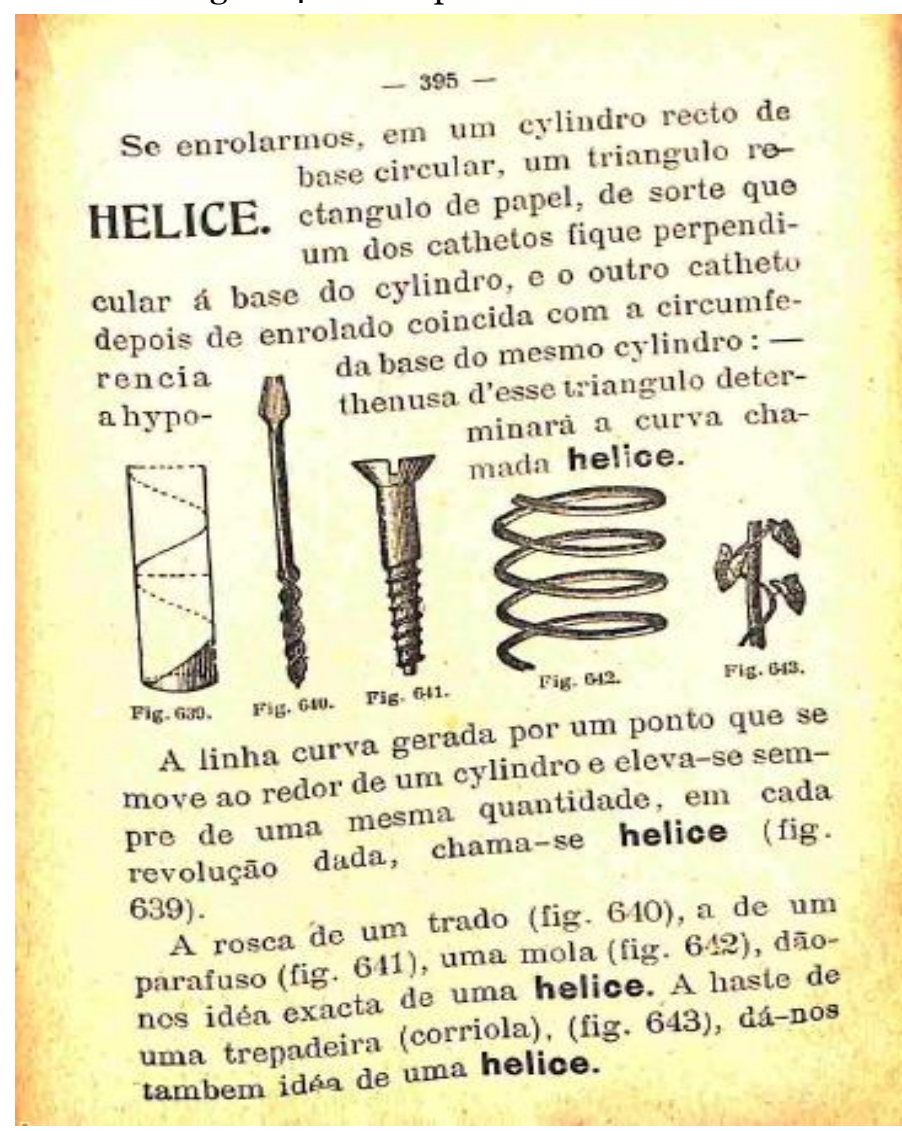

Fonte: Freire (1930, p. 395).

ISSN 2526-2882 
O segundo tipo de ilustração identificada no livro, o desenho, apareceu em dezessete dos vinte e um capítulos, sendo o capítulo 8 o que mais apresentou essa tipologia. Já os capítulos 11, 14, 18 e 20 não apresentaram ilustrações desse tipo. Exemplo desse tipo de ilustração é apresentado na Figura 4.

Ao apresentar a definição de hélice, o autor oferece desenhos de rosca, parafuso, mola e hastes de uma trepadeira como exemplos específicos do objeto geométrico determinado por uma hélice. Essa situação permite compreender a diferença entre esquema e desenho, pois "[...] o esquema elimina o máximo de elementos irrelevantes e, portanto, apresenta um caráter de generalidade: o objeto desenhado é representativo de um conjunto" (VEZIN, L., 1986, p. 110).

Muitas das ilustrações identificadas como desenho são caracterizadas por objetos do cotidiano dos alunos, como se observa no estudo dedicado à hélice. Essa era uma forma de fazer com que as ilustrações estivessem mais próximas à ideia dos objetos reais, auxiliando quanto ao uso do método intuitivo no estudo das definições de figuras geométricas.

Além do objetivo de enfatizar o uso de objetos cotidianos do aluno, o desenho também indicava outras concepções importantes para a época, conforme nos indica a Figura 5.

Figura 5 - Exemplo de desenho II

$$
-129-
$$

a curva que conhecemos pelo nome de cipcumferencia (fig.289).

Adaptado á ponta movel empregamos geralmente o giz, o lapis, o carvâo.

Em um terreno plano, fixamos uma estaca na qual prendemos, por uma fig. 285,- stodo detracar una das extremidrdes, um

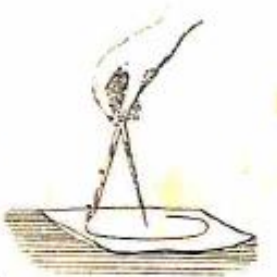
cordel, e na outra extremidade é collocada uma ponteira ou uma vara destinada a traçar a circumferencia (fig. 290). A estaca

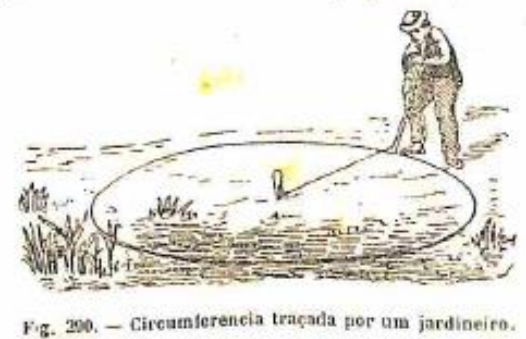

occupa o centro, o cordel bem esticado e o raio e a ponteira ou a vara risea a circumferencia.

X Problema 108. - Fazer passar uma circumferencia por tres pontos não em linha recta.

Fonte: Freire (1930, p. 129). ISSN 2526-2882 
No estudo da circunferência, os desenhos utilizados estão relacionados ao uso de instrumentos de construção de figuras e com uma atividade profissional, a jardinagem. Esse resultado está de acordo com Trinchão (2008), que mostra, em sua tese de doutorado, a concepção de utilidade do desenho como uma inserção no espaço escolar que "[...] deveria ser entendida aos homens de todas as profissões" (p. 232).

Assim, relacionar a Geometria ao seu uso na vida profissional era uma forma de mostrar o seu valor prático ao indicar suas várias aplicações na vida cotidiana e também auxiliaria na formação de futuros trabalhadores. Essa ideia também é justificada com as ilustrações utilizadas para o estudo da hélice, que eram relacionadas aos objetos existentes em várias profissões e na indústria.

Outro tipo de ilustração, além do esquema e do desenho, identificado na análise, foi o desenho esquematizado, com um total de 16 ilustrações, que se distingue pelo fato de apresentar características tanto do desenho quanto do esquema, como nos apresenta o exemplo da Figura 6.

Figura 6 - Exemplo de desenho esquematizado

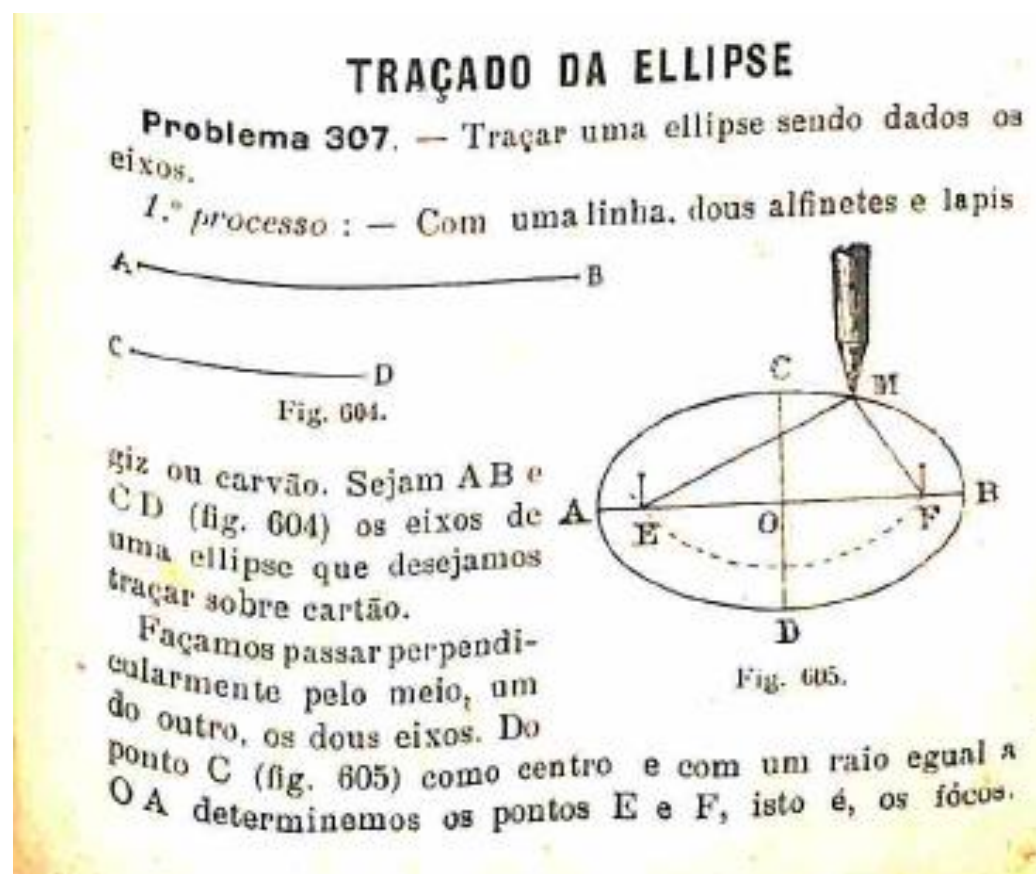

Fonte: Freire (1930, p. 129).

Para o traçado da elipse, pode-se dizer que o autor utiliza um desenho esquematizado. Trata-se de um esquema porque são indicados elementos que se relacionam à definição da elipse, como seus focos $\mathrm{E}$ e $\mathrm{F}$ e eixos $\mathrm{AB}$ e $\mathrm{CD}$. Também há elemento que caracteriza um desenho ao incluir a representação de um giz ou carvão, indicando, assim, um traçado 
específico de determinada elipse, ou seja, um objeto representativo de todo um conjunto conhecido como elipse.

A função motivacional contextual foi possível ser identificada em algumas ilustrações ao longo do livro, como nos exemplos das figuras 4, 5 e 6, pois as representações de objetos e práticas cotidianas nas ilustrações procuravam, além de estar em consonância às novas metodologias propostas, tornar o texto mais atraente ao leitor e auxiliar quanto ao desenvolvimento de futuras profissões.

Em face ao exposto, em Noções de Geometria Pratica, de modo geral, Freire (1930) ao abordar o conteúdo expresso no sumário apresenta no início de cada capítulo, uma contextualização do tema abordado com a vida cotidiana do aluno, posteriormente são colocadas algumas consequências/extensões, particularidades, propriedades e aplicação (teórica), como no exemplo a seguir:

Figura 7 - Aproximação do conteúdo com o cotidiano do aluno

CAPITULO I

PRIMEIRAS DEFINIÇÕES

SUMMARIO : Espaço. - Gorpo. - Extensão. -

Volume. - Superficie. - Linha. - Ponto.

Si collocarmos um tinteiro sobre uma mesa, elle fica em uma posição determinada no espaço.

ESPAÇO. A mesa está no espaço limitado pela sala; esta no espaço comprehendido pela escóla; a escóla sobre a Terra; e a Terra, em continuo movimento pelo espaço.

Fonte: Freire (1930, p. 9)

No conteúdo (espaço), o autor não apresentou figuras, apenas fez referências a material escolar e mobília que o aluno conhecia, trazendo aproximação com o ambiente escolar. Com esses elementos, ele traz uma definição de espaço e utiliza a primeira ilustração para fazer conexão com os assuntos apresentados no sumário do início de cada capítulo.

ISSN 2526-2882 
Figura 8 - Contextualização

$$
-10-
$$

espaço : porém que espaço? - Onde principia ou acaba?

0 espaço, sem ter começo nem fim, encerra todas as cousas e estende-se em todas as direccōes.

Todas as cousas que occupam um certo logar no espaço chamam-se corpos.

CORPO. Assim um tinteiro, uma uma folha, etc. occupam um certo logar no espaço e são por isso chamados corpos. (fig. 1).

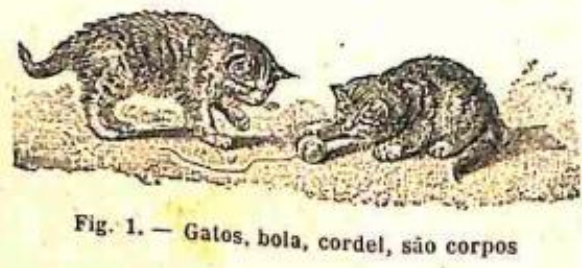

Fonte: Freire (1930, p. 10).

Frente a esse posicionamento, quanto a abordagem dos conteúdos, Freire (1930), objetivava ensinar aos alunos observar, nomear e comparar, o que se lhe apresentava, para deixar agir seus instintos intelectuais, ações essas características do método intuitivo.

\section{Algumas considerações}

Na análise do livro de Freire (1930), foi possível identificar vários tipos e funções relacionadas às ilustrações utilizadas. O presente estudo trouxe elementos importantes e que auxiliaram na discussão sobre o ensino da Geometria no início do período republicano. A maioria das ilustrações tinha características da função explicativa descritiva, cuja intenção era fazer com que ela auxiliasse na elaboração de uma imagem mental relacionada ao conceito abstrato, permitindo, assim, uma concretização dos conceitos e propriedades que eram de difícil compreensão.

Outro resultado importante foi verificar que os vários passos necessários às construções geométricas propostas por Freire tornaram-se possíveis por meio de esquemas que tinham a função descritiva funcional, pois cada um dos passos era explicado no texto 
escrito e identificado na respectiva ilustração por meio de linhas tracejadas. Os desenhos utilizados por Freire também procuraram trazer elementos da vida cotidiana para o texto. $\mathrm{O}$ ensino da Geometria também tinha a preocupação de mostrar objetos utilizados no dia a dia, assim como os relacionados às variadas profissões.

Assim, as ilustrações foram desenvolvidas com o objetivo de auxiliar na propagação do método intuitivo. Elas procuravam auxiliar no desenvolvimento de passos metódicos para o desenvolvimento de ideias, método em que a observação era essencial à aprendizagem e que tinha como principal objetivo a educação dos sentidos. Além disso, procuravam chamar a atenção dos alunos e auxiliar na qualificação dos futuros trabalhadores republicanos.

Foi interessante observar que, por meio do livro didático, Olavo Freire apresentou uma apropriação criativa com relação às metodologias que estavam sendo difundidas. A sua tentativa foi de inserir ideias que eram propagadas pelos especialistas da educação e ao mesmo tempo auxiliar professores e alunos na compreensão do que era apresentado em seu livro e, nesse caso, as ilustrações tiveram um papel de destaque

\section{Referências}

BARBOSA, R. Reforma do ensino primário e várias instituições complementares da instrução pública. v. X, t. II, 1883. Rio de Janeiro: Ministério da Educação e Saúde, 1946. (Coleção Obras Completas de Rui Barbosa).

CERTEAU, M De. A escrita da história. Trad. Maria de Lourdes Menezes. Rio de Janeiro: Forense, Universitária, 2005.

CHARTIER, R. A história cultural: entre práticas e representações. Lisboa: DIFEL, 1990.

D’ESQUIVEL, M O. A obra Primeiras Noções de Geometria Prática de Olavo Freire: a mão do autor e mente do editor. Revista Educação Matemática em Foco, v. 7, n. 1, p.2$20,2018$.

FREIRE, O. Noções de Geometria Prática. 35. ed. Rio de Janeiro: Livraria Francisco Alves, 1930.

LEME DA SILVA, M C; VALENTE, W R. A geometria nos grupos escolares. In: SILVA, Maria Célia Leme da; VALENTE, Wagner Rodrigues (Org.). A geometria nos primeiros anos escolares: história e perspectivas atuais. Campinas, SP: Papirus, 2014.

. Práticas de desenho e saberes geométricos nos manuais escolares do século XIX. Proposições, v. 29, n. 2 (87), maio/ago., p. 352-369, 2018.

MACHADO, M C G. Rui Barbosa: pensamento e ação: uma análise do projeto modernizador para a sociedade brasileira com base na questão educacional. Campinas, SP: Autores Associados; Rio de Janeiro, RJ: Fundação Casa de Rui Barbosa, 2002. 
PERAYA, D; NYSSEN, M-C. Les illustrations dans les manuels scolaires: vers une théorie générale des paratextes. Mscope, n. 7, p. 8-12, 1994. Disponível em: <https://archive-ouverte.unige.ch/unige:17348>. Acesso em: 12 set. 2018.

SOUZA, R F de. Alicerces da Pátria: história da escola primária no estado de São Paulo (1890-1976). Campinas, SP: Mercado de Letras, 2009.

VALDEMARIN, V T. O método intuitivo: os sentidos como janelas e portas que se abrem para um mundo interpretado. In: SAVIANI, Dermeval et al. O legado educacional do século XIX. 3. ed. Campinas, SP: Autores Associados, 2004. p. 81-126. (Coleção Educação Contemporânea).

VEZIN, L. Les illustrations, leur rôle dans l'apprentissage des textes. Enfance, tome 39, n. 1, 1986. p. 109-126. Disponível em: <http://www.persee.fr/doc/enfan_o0137545_1986_num_39_1_2911>.Acesso em: 2 ago. 2018.

VEZIN, J-F. Schématisation et acquisition des connaissances. In: Revue française de pédagogie, v. $77, \quad$ 1986. p. 71-78. Disponível em: <https://www.persee.fr/doc/rfp_0556-7807_1986_num_77_1_1495>. Acesso em: 2 ago. 2018.

\section{Biografia Resumida}

Alexsandra Camara: Possui graduação em Licenciatura em Matemática e mestrado em Educação Matemática pela Pontificia Universidade Católica de São Paulo (2004). Tem experiência na área de ensino de Matemática na Educação Básica e Ensino Superior (presencial e a distância). Atualmente, realiza doutorado em Educação com pesquisa inserida na área de História da Educação Matemática na Pontifícia Universidade Católica do Paraná.

e-mail: ale-prof@hotmail.com

Link Lattes: http://lattes.cnpq.br/2798127549726092

Zenildo Santos: Professor da Educação Básica, possui graduação em Letras vernáculas pela Universidade do Estado da Bahia (2007), graduado em Literatura e Ensino de Literatura, pela Universidade Estadual do Sudoeste da Bahia (2011), graduação em Matemática pela Universidade Estadual do Sudoeste da Bahia (2017) e mestrado em Ciências e Matemática Universidade Estadual do Sudoeste da Bahia (2019).

Link Lattes: http://Link Lattes.cnpq.br/3266291362839017

e-mail: zenildo198090@gmail.com

ISSN 2526-2882 